\title{
Correction: Hospital admissions for stroke and bleeding in Hounslow following a quality improvement initiative
}

Wong KY, Davies B, Adeleke Y, et al. Hospital admissions for stroke and bleeding in Hounslow following a quality improvement initiative. Open Heart 2021;8:e01558.

Since the publication of this article, the authors have noticed that the figures were displayed in the wrong order and therefore mismatched with their captions. This has now been corrected. The correct figures and their captions are shown below (figures 1-5).

Figure 1 Proposed impact model with a level change for the ITS analysis. Red solid line=preintervention trend; red dashed line $=$ counterfactual; blue line=postintervention trend; $\beta 0=$ intercept representing starting level of outcome variable; $\beta 1=$ slope prior to intervention; $\beta 2=$ change in level after intervention; $T=$ time since start of the study; $\mathrm{X}=$ intervention. ITS, interrupted time series.

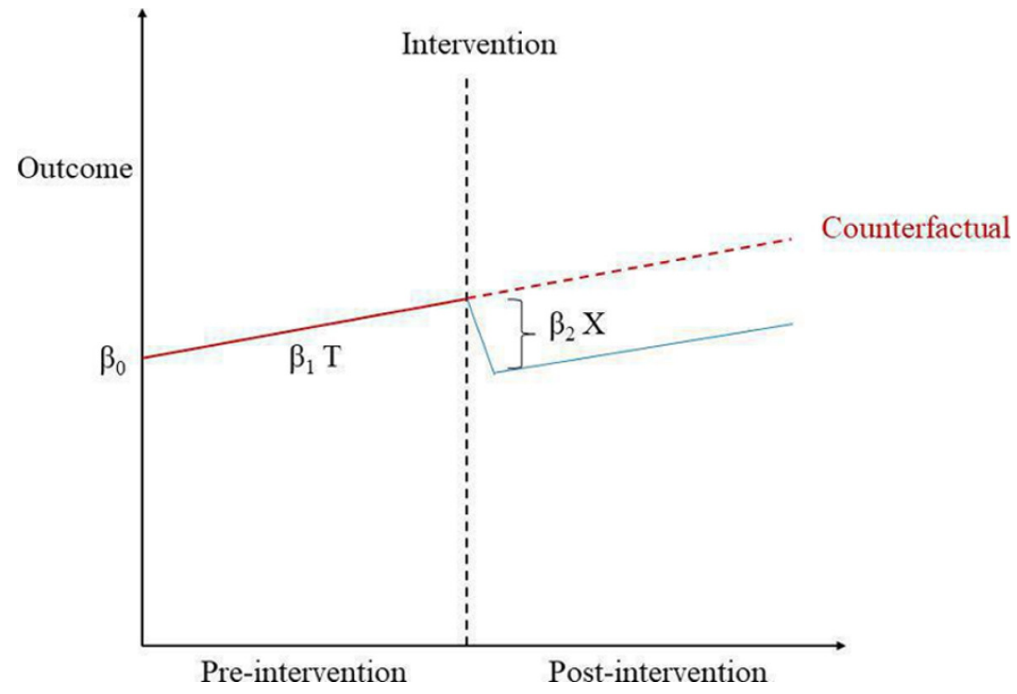

Figure 2 Seasonality adjusted ITS regression showing age-sex-standardised rate of admission with stroke as primary diagnosis in Hounslow CCG from January 2011 to August 2018. Grey vertical line: Intervention time point. Level change in relation to intervention variable: IRR 0.83; 95\% CI 0.721 to 0.963 ; $\mathrm{p}<0.014$. AF, atrial fibrillation; CCG, Clinical Commissioning Group; IRR, incidence rate ratio; ITS, interrupted time series.

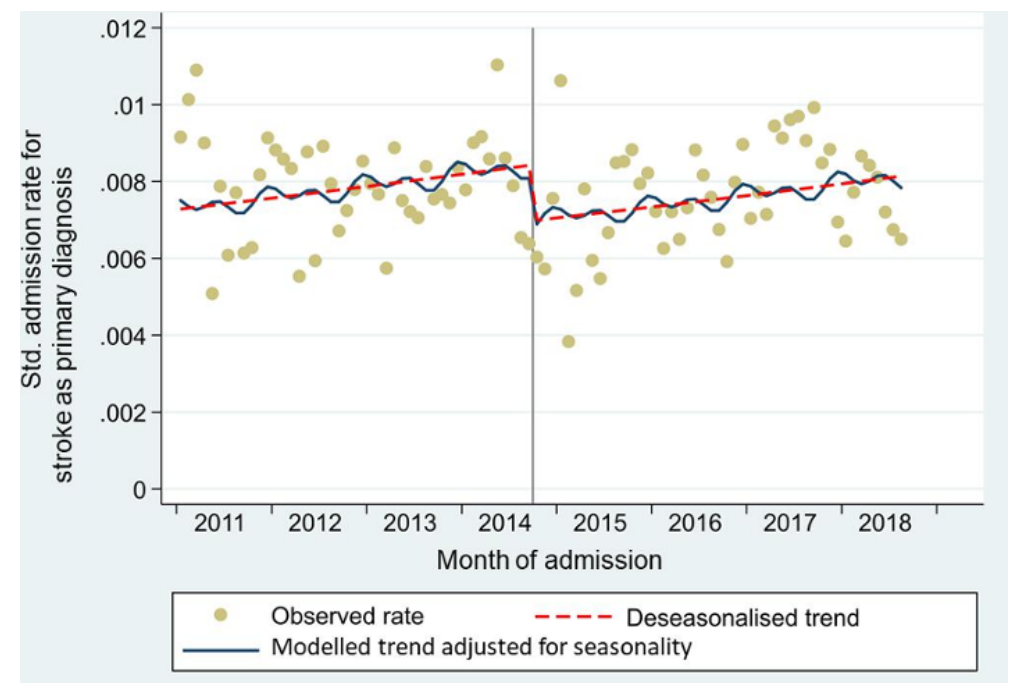


Figure 3 Seasonality adjusted ITS regression showing age-sex-standardised rate of admission with stroke as primary diagnosis and $\mathrm{AF}$ as secondary diagnosis in Hounslow CCG from January 2011 to August 2018. Grey vertical line: Intervention time point. Level change in relation to intervention variable: IRR 0.75 ; $95 \%$ CI 0.550 to 1.025 ; $\mathrm{p}<0.071$. AF, atrial fibrillation; CCG, Clinical Commissioning Group; IRR, incidence rate ratio; ITS, interrupted time series.

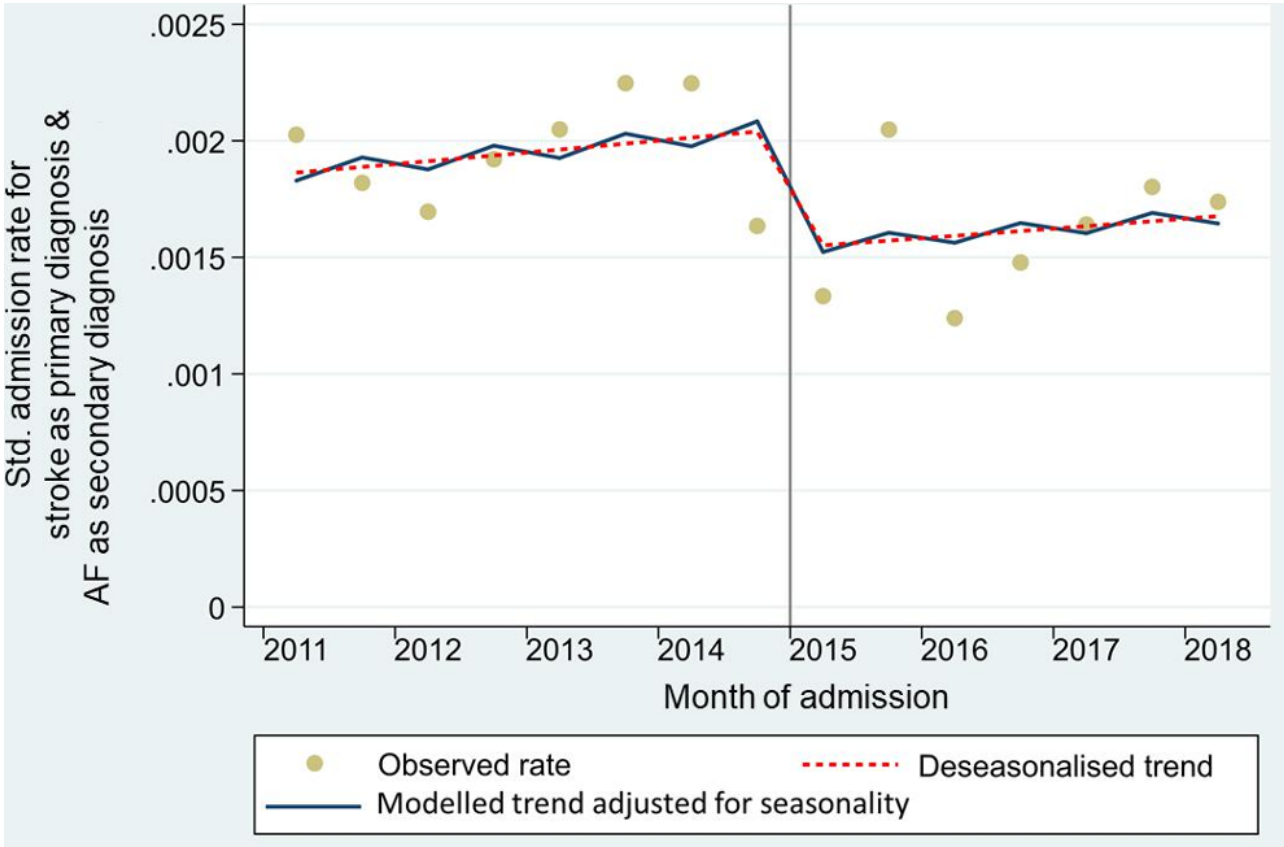

Figure 4 Seasonality adjusted ITS regression showing age-sex-standardised rate of admission with bleeding as primary diagnosis and $\mathrm{AF}$ in any position of diagnosis in Hounslow CCG from January 2011 to August 2018. Grey vertical line: Intervention time point. Level change in relation to intervention variable: IRR $0.93 ; 95 \%$ CI 0.597 to $1.449 ; \mathrm{p}<0.749$. AF, atrial fibrillation; CCG, Clinical Commissioning Group; IRR, incidence rate ratio; ITS, interrupted time series.

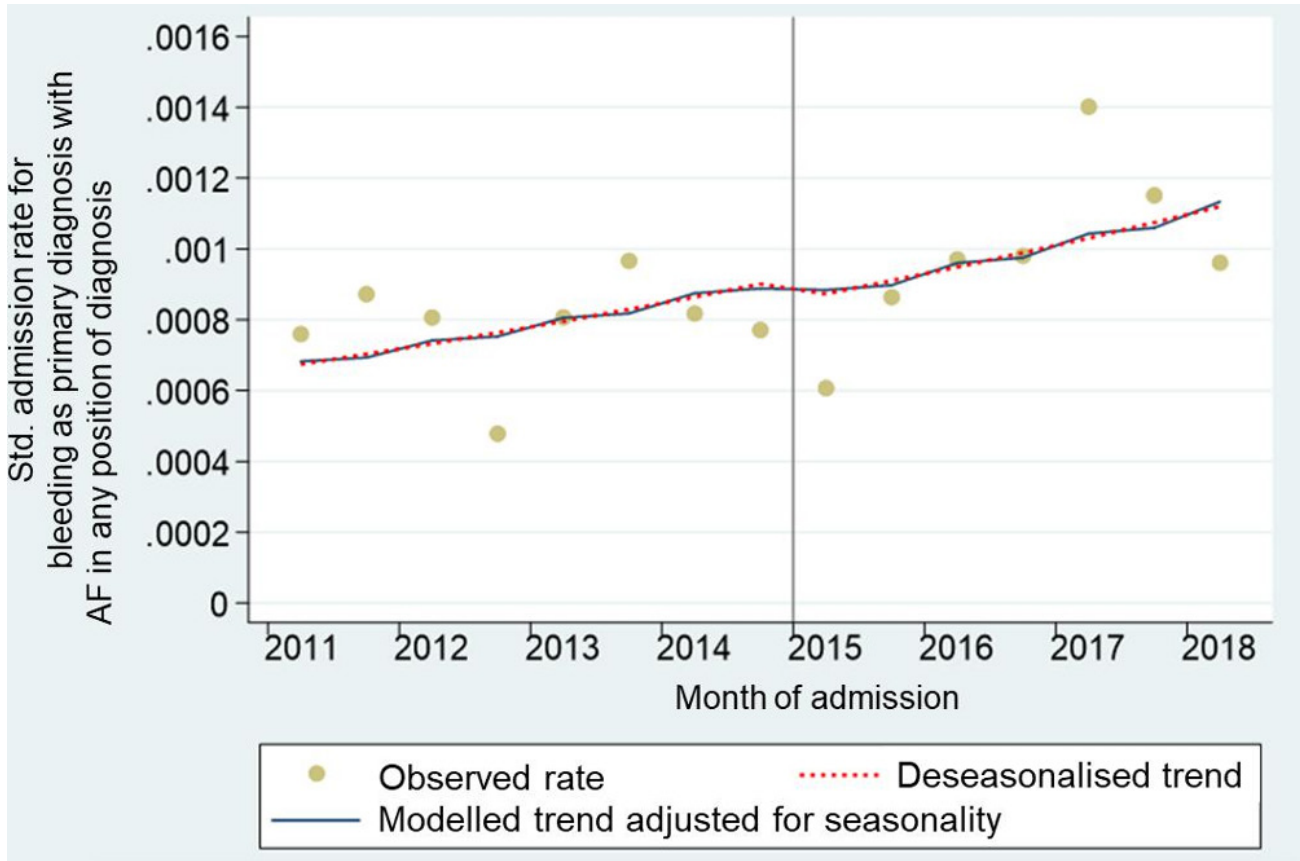


Figure 5 Seasonality adjusted ITS regression showing age-sex-standardised rate of admission with bleeding as primary diagnosis and use of OAC as secondary diagnosis in Hounslow CCG from January 2011 to August 2018. Grey vertical line: intervention time point. Level change in relation to intervention variable: IRR 0.92; 95\% CI 0.520 to 1.621; $\mathrm{p}<0.769$. CCG, Clinical Commissioning Group; IRR, incidence rate ratio; ITS, interrupted time series; OAC, oral anticoagulation.

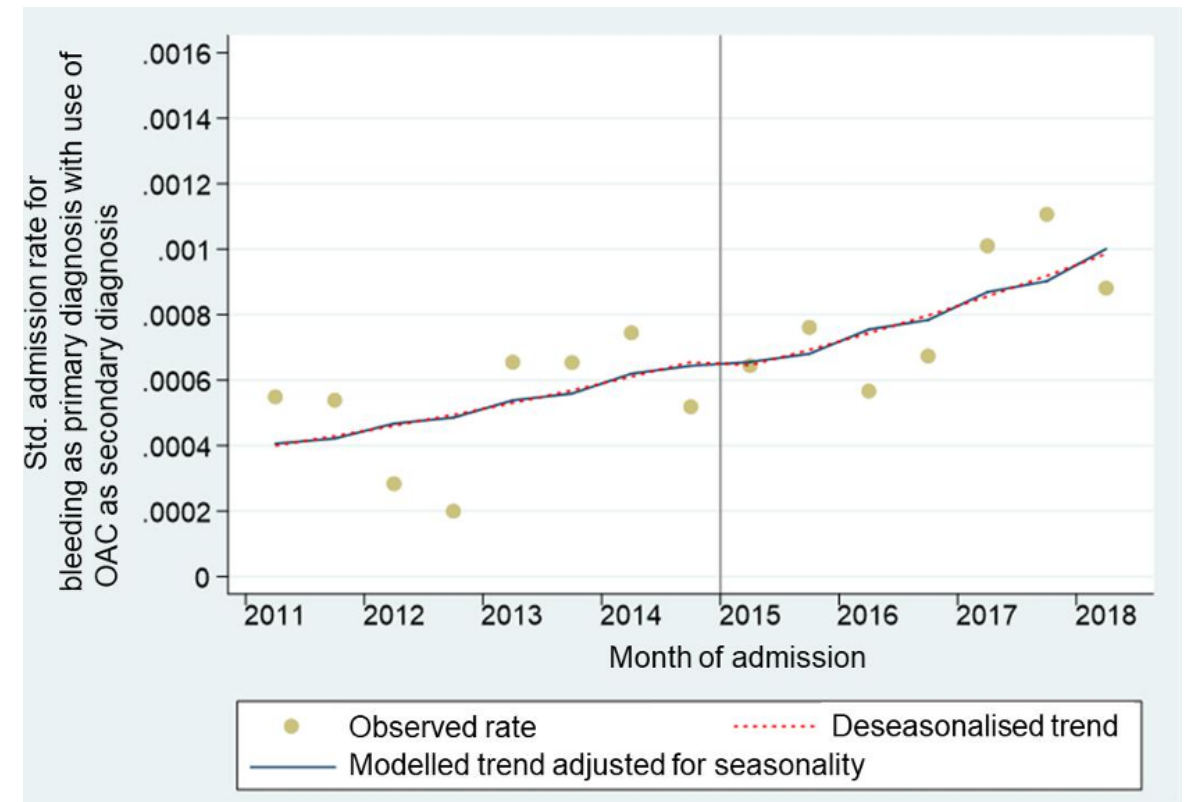

Open access This is an open access article distributed in accordance with the Creative Commons Attribution Non Commercial (CC BY-NC 4.0) license, which permits others to distribute, remix, adapt, build upon this work non-commercially, and license their derivative works on different terms, provided the original work is properly cited, appropriate credit is given, any changes made indicated, and the use is non-commercial. See: http://creativecommons.org/licenses/by-nc/4.0/.

(c) Author(s) (or their employer(s)) 2021. Re-use permitted under CC BY-NC. No commercial re-use. See rights and permissions. Published by BMJ.

Open Heart 2021;8:e001558corr1. doi:10.1136/openhrt-2020-001558corr1

A) Check for updates 